\title{
NEW ADJUVANT TECHNOLOGY FOR PESTICIDE USE ON WINE GRAPES
}

\author{
R.E GASKIN ${ }^{1}$, D.W. MANKTELOW ${ }^{2}$ and G.S. ELLIOTT ${ }^{3}$ \\ ${ }^{1}$ Forest Research, Private Bag 3020, Rotorua \\ ${ }^{2}$ HortResearch, Private Bag 1401, Havelock North \\ ${ }^{3}$ Elliott Chemicals Ltd, P O Box 18-417, Glen Innes, Auckland \\ Corresponding author: robyn.gaskin@forestresearch.co.nz
}

ABSTRACT

Wine grape growing is under increasing pressure to reduce pesticide use. A project was undertaken to develop new adjuvant prescriptions to reduce spray volumes required throughout full-season pesticide programmes in vineyards and to improve spray coverage and retention on foliage and grape bunches. A pre-harvest field trial confirmed improved targeting of Chardonnay foliage and bunches with markedly lowered spray application volumes when a novel organosilicone adjuvant, Du-Wett, was included in the spray mix. Application volumes of $\leq 200$ litres/ha maximised retention and distribution of pesticide sprays containing the organosilicone. The optimal Du-Wett rate required in sprays targeting foliage was lower (0.2-0.4 litres/ha) than that in sprays directed at grape bunches (0.2-0.8 litres/ha). The results suggest spray application volumes on grapes could be greatly reduced with use of appropriate adjuvants, without compromising pesticide efficacy.

Keywords: organosilicone surfactants, spray coverage, spray retention, spray volume.

\section{INTRODUCTION}

Wine grape growing is pesticide intensive and, like other horticultural operations, is coming under increasing pressure to reduce pesticide use, avoid spray drift and minimise soil and water contamination. Traditional spray programmes in New Zealand vineyards involve high volume application of agrochemicals to wet canopies to the point of run-off. Such high volumes are inefficient in terms of spray losses through drift and runoff, droplet sizes that limit canopy penetration and coverage, low work rates and high use of water resources. The products available to grape growers to control pests and diseases are limited and the industry represents too small a market to warrant the development of major agrochemical products specifically for its use. Thus, growers increasingly need to modify formulations and application systems to improve the efficacy of their spray programmes.

Spray adjuvants are at the forefront of a global trend to customise pesticides for specific applications and to reduce environmental contamination by maximising pesticide efficacy (Underwood et al. 2001). In New Zealand, recent studies with organosilicone adjuvants have demonstrated their ability to improve the effectiveness of growers' spray programmes in kiwifruit (Gaskin et al. 2001a), potato (Gaskin et al. 2000a) and onion (Gaskin et al. $2001 b$ ) crops. The objective of this study was to determine the potential of novel organosilicone adjuvant blends to reduce agrochemical spray volumes while maintaining, or improving, retention and coverage of sprays on grape bunches and foliage.

\section{MATERIALS AND METHODS}

The two organosilicone adjuvant blends investigated in this study were Du-Wett (Elliott Chemicals Ltd) and Bond Xtra (Loveland Industries, USA), a superspreader and stickerspreader, respectively. These adjuvants, and their properties, have been described previously (Gaskin et al. 2000b). Citowett (alkylaryl polyglycol ether; BASF), a commonly-used horticultural adjuvant, was included for comparison at the rate recommended on the label 
(25 ml/100 litres). Spreading measurements, as described by Gaskin et al. (2000b), were made in the laboratory on freshly detached leaves from outdoor-reared grape plants (cv. Chardonnay) and on red table grapes (ex-USA) sourced from a local supermarket. Spreading of more than 30 combinations of active ingredients regularly applied as mixtures in vineyard spray programmes (S. Bradley, Delegats, pers. comm.), was determined with the addition of up to seven adjuvant rates, on both leaves and berries.

Retention studies were conducted in the field on a mature, well leaf-plucked VSP Chardonnay canopy, located in the HortResearch vineyard in Hawke's Bay, immediately prior to harvest (April). Treatments were applied with a Cropliner $820 \mathrm{~mm}$ diameter axial fan airblast sprayer under warm, still conditions using the low fan speed (ca $30,000 \mathrm{~m}^{3} / \mathrm{h}$ air output). Applications were made at $5.4 \mathrm{~km} / \mathrm{h}$, with different combinations of Spraying Systems hollow cone TX nozzles and operating pressures used to deliver the different application volumes required. Four nozzles were used to target the canopy in each case, with outputs divided so that the lower two nozzles delivered 55-60\% of the spray plume into the bunch zone (a ca $400 \mathrm{~mm}$ vertical swath), with the output from the upper two nozzles directed to the remainder of the canopy (a ca $900 \mathrm{~mm}$ vertical swath). All treatments contained pyrimethanil ( $800 \mathrm{~g}$ ai/ha; Scala, BASF) and tartrazine dye (10 g/litre). Bunches ( 5 bunches/replicate; 5 replicates/treatment) and foliage (6 leaves/replicate; 5 replicates/ treatment) were collected immediately after spraying and stored in sealed plastic bags in the dark in a cool store prior to analysis. Leaves were sampled from outer and inner positions at three canopy heights: bunch line, mid-canopy and upper-canopy positions. Samples were washed in known aliquots of distilled water and dye absorbance determined as described previously (Murray et al. 1998). Leaf areas were determined with a Licor LI3100 Leaf Area Meter and bunches were weighed fresh. Retention results were normalised at $1 \mathrm{~kg} / \mathrm{ha}$ dye application to enable comparison of treatments. Analysis of variance and least significant difference (LSD) tests at $\mathrm{P}<0.05$ were used to compare treatment means.

\section{Spreading}

\section{RESULTS AND DISCUSSION}

A selection of spreading results are presented in Table 1 to illustrate the main effects of the adjuvants and their interactions with formulations and plant surfaces. As expected of a superwetter, Du-Wett enhanced spreading of all formulations; coverage increased with increasing concentration and often the response was linear. Bond Xtra spray solutions overall spread much less than Du-Wett, but when used at high rates, Bond Xtra also exhibited superspreading activity due to its organosilicone component. Waxy grapes were more difficult to wet than foliage and formulations required higher adjuvant rates to achieve good spreading on fruit.

TABLE 1: Spreading $\left(\mathrm{mm}^{2}\right)$ of $0.5 \mu$ droplets of different adjuvant-spray formulations on grape leaves and bunches.

\begin{tabular}{|c|c|c|c|c|c|c|c|}
\hline \multirow[t]{2}{*}{ Adjuvant } & \multirow{2}{*}{$\begin{array}{c}\text { Adjuv. conc. } \\
(\% \mathrm{v} / \mathrm{v})\end{array}$} & \multicolumn{3}{|c|}{ Adaxial leaf surface } & \multicolumn{3}{|c|}{ Berry surface } \\
\hline & & $\mathrm{m}+\mathrm{s}^{1}$ & $c+s$ & $c+c p$ & $\mathrm{~m}+\mathrm{s}$ & $\mathrm{c}+\mathrm{s}$ & $c+c p$ \\
\hline Citowett & 0.025 & $2 \mathrm{~d}^{2}$ & $4 \mathrm{e}$ & $3 \mathrm{~d}$ & $2 \mathrm{e}$ & $3 \mathrm{~d}$ & $4 \mathrm{de}$ \\
\hline Du-Wett & 0.05 & $13 \mathrm{c}$ & $21 \mathrm{~cd}$ & $10 \mathrm{c}$ & $6 \mathrm{~cd}$ & $8 \mathrm{~b}$ & $5 \mathrm{bc}$ \\
\hline Du-Wett & 0.10 & $29 \mathrm{~b}$ & $43 \mathrm{~b}$ & $30 \mathrm{~b}$ & $12 \mathrm{~b}$ & $7 \mathrm{bc}$ & $6 \mathrm{~b}$ \\
\hline Du-Wett & 0.20 & $40 \mathrm{a}$ & $88 \mathrm{a}$ & $49 \mathrm{a}$ & $19 \mathrm{a}$ & $13 \mathrm{a}$ & $9 \mathrm{a}$ \\
\hline Bond Xtra & 0.10 & $3 \mathrm{~d}$ & $5 \mathrm{e}$ & $4 \mathrm{~cd}$ & 3 de & $4 \mathrm{~cd}$ & $3 \mathrm{e}$ \\
\hline Bond Xtra & 0.20 & $4 \mathrm{~d}$ & $11 \mathrm{de}$ & $5 \mathrm{~cd}$ & 4 cde & $4 \mathrm{~cd}$ & 4 cde \\
\hline Bond Xtra & 0.40 & $10 \mathrm{c}$ & $27 \mathrm{c}$ & $10 \mathrm{c}$ & $7 \mathrm{c}$ & 5 bcd & 5 bcd \\
\hline
\end{tabular}

${ }^{1} \mathrm{~m}=$ mancozeb, $\mathrm{s}=$ liquid sulphur, $\mathrm{c}=$ captan, $\mathrm{cp}=$ chlorpyrifos.

${ }^{2}$ Treatment means within columns sharing common letters are not significantly different $(\mathrm{P}<0.05)$. 
Agrochemical formulations can have varying and often unpredictable effects on the spreading properties of organosilicone adjuvants (Gaskin et al. 2000b) and this was highlighted in this study. Conventional adjuvants such as Citowett are affected little by "in-can" formulants of active ingredients because these adjuvants promote comparatively little droplet spread. In contrast, the superspreading of organosilicones may be reduced or enhanced by different formulations (Table 1). If organosilicone use is to be optimised this must be taken into account when prescribing treatments. For example, Du-Wett addition to mancozeb+sulphur provided excellent foliage coverage at $0.2 \%$. When captan was combined with sulphur, spreading of the spray solution was effectively doubled, increasing the likelihood of run-off and hence, reduced efficacy. In contrast, when chlorpyrifos was included in tank mix with captan, some antagonism of organosilicone spreading properties may have resulted in less than expected spray coverage of foliage, compared to captan+sulphur. A similar pattern is seen with Bond Xtra at $0.4 \%$, the highest rate. When the spray target was fruit, which is more difficult to wet, such differences were not so apparent and the relativity between treatments was changed completely. Our results confirm that interactions between adjuvant formulations and plant surfaces are not always easy to predict.

Spray retention and distribution on field vines

The systematic retention study confirmed the potential of Du-Wett to markedly reduce spray volumes on grapevines, but highlighted the importance of matching organosilicone adjuvant concentration with application volume to achieve improved spray retention and distribution (Tables $2 \& 3$ ). Traditionally, spray tank adjuvant recommendations are given in terms of percentage volume of adjuvant in the spray (\% v/v), but recent studies with organosilicones have suggested that recommendations based on volume per area (litres/ha) may be a better way of prescribing these adjuvants (Humble \& Burga 2001; Gaskin et al 2000a, 2001b). Results from this study endorse that recommendation.

TABLE 2: Retention and distribution of pyrimethanil sprays on Chardonnay foliage with varying adjuvant rate and spray volume.

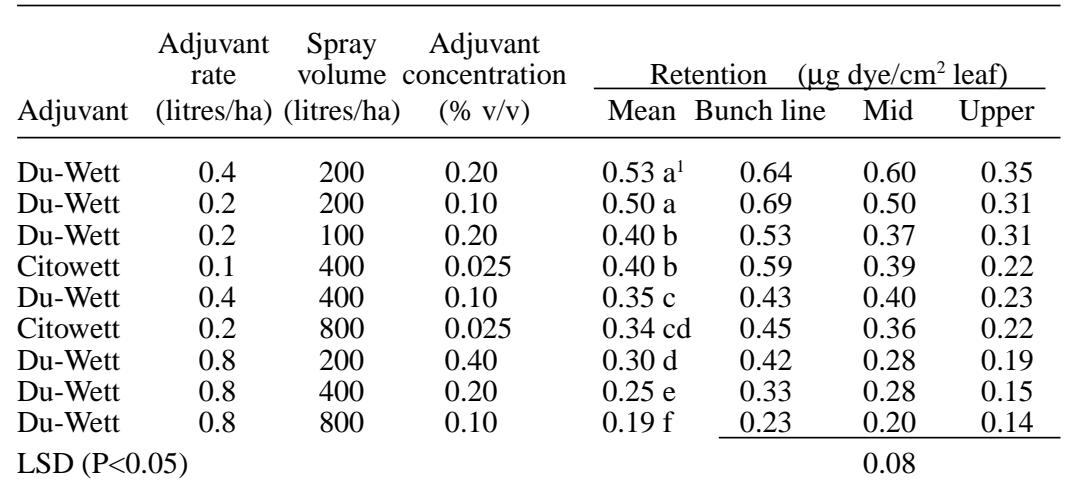

${ }^{1}$ Treatment mean values sharing common letters are not significantly different (LSD, $\mathrm{P}<0.05)$.

Generally, on easy-to-wet foliage, sprays were retained better at lower spray volumes, especially on the exposed bunch-line (Table 2). Greatest retention was with 0.4 litres/ha of Du-Wett, applied in 200 litres/ha spray volume, which was significantly better than with high volumes of Citowett spray $(\mathrm{P}<0.05)$. When the Du-Wett rate was $>0.4$ litres/ha or the spray volume $>200$ litres/ha, then retention was reduced. The increased risk of spray run-off when using a superwetter in high volume sprays is illustrated, with Citowett generally providing better retention than Du-Wett when applied in $\geq 400$ litres/ha. The leaf position (inner vs outer) had no significant effect on spray distribution in this open- 
leaf canopy $(\mathrm{P}>0.05)$. Spray was targeted at mature fruit in the bunch line and as expected, the height position of leaves on the canopy was highly significant $(\mathrm{P}<0.0001)$. More spray was retained on foliage at the low bunch line position than at the mid-canopy, which in turn captured more spray than the upper canopy. This may also be a function of recapturing run-off from foliage above. The low-volume/low-rate Du-Wett sprays (200 litres/0.2 litres/ha) were retained more by leaves at all heights in the canopy than were conventional high-volume Citowett sprays.

On waxy grape bunches, the expected trend for better retention with higher volume of Citowett sprays was confirmed (Table 3 ). In contrast, Du-Wett spray was best retained at 200 litres/ha, using an adjuvant rate of 0.4 litres/ha. In general, decreasing spray volume increased the retention of Du-Wett sprays on bunches and greater or equal amounts of active ingredient were captured, at four times less the application volume, compared to Citowett sprays.

The retention data on both foliage and bunches suggests that spray application volumes on wine grapes could be markedly reduced using organosilicone adjuvants without compromising pesticide efficacy. Application volumes should be $\leq 200$ litres/ha to maximise spray retention and distribution. Du-Wett rates should be lower in sprays targeting foliage than for those directed at grape bunches. Higher rates of Du-Wett may be beneficial as canopy density or bunch size and complexity increase, but spray volumes should be minimised to prevent losses to runoff.

TABLE 3: Retention of pyrimethanil sprays on Chardonnay bunches with varying adjuvant rate and spray volume.

\begin{tabular}{lcccc}
\hline Adjuvant & $\begin{array}{c}\text { Adjuvant rate } \\
\text { (litres/ha) }\end{array}$ & $\begin{array}{c}\text { Spray volume } \\
(\text { litres/ha) }\end{array}$ & $\begin{array}{c}\text { Adjuvant conc. } \\
(\% \mathrm{v} / \mathrm{v})\end{array}$ & $\begin{array}{c}\text { Retention } \\
(\mu \mathrm{g} \text { dye/g fresh wt })\end{array}$ \\
\hline Du-Wett & 0.4 & 200 & 0.20 & $1.07 \mathrm{a}^{1}$ \\
Du-Wett & 0.2 & 200 & 0.10 & $0.93 \mathrm{ab}$ \\
Du-Wett & 0.2 & 100 & 0.20 & $0.90 \mathrm{abc}$ \\
Du-Wett & 0.4 & 400 & 0.10 & $0.89 \mathrm{abc}$ \\
Citowett & 0.2 & 800 & 0.025 & $0.81 \mathrm{bc}$ \\
Du-Wett & 0.8 & 200 & 0.40 & $0.81 \mathrm{bc}$ \\
Citowett & 0.1 & 400 & 0.025 & $0.74 \mathrm{~cd}$ \\
Du-Wett & 0.8 & 800 & 0.10 & $0.58 \mathrm{de}$ \\
Du-Wett & 0.8 & 400 & 0.20 & $0.54 \mathrm{e}$
\end{tabular}

${ }^{1}$ Values sharing common letters are not significantly different (LSD, $\left.\mathrm{P}<0.05\right)$.

\section{CONCLUSIONS}

The preliminary trial work on grapes described in this paper highlights both the potential and some of the problems that are likely to be encountered in the use of adjuvants. The application rates required for organosilicone adjuvants are a relatively complex function of agrochemical mixes and rates, spray application volumes, canopy type and the target canopy tissues (leaves, wood or bunches of fruit). Extensive vineyard trials to determine the field performances of Du-Wett and Bond Xtra on a variety of grape canopies are currently underway. The results of these will be used to develop prescriptions for adjuvant use that will allow growers to maximise the pest and disease control potential of their agrochemicals, while improving the cost-effectiveness of their spray applications.

\section{ACKNOWLEDGEMENTS}

Technology New Zealand supported this study through a Technology for Business Growth grant. OSi Specialties (Crompton Corp., USA) and Loveland Industries (USA) 
provided some financial assistance. Thanks to Rachel Murray, Kevin Steele, Bernadette Nanayakkara, Linda Lester and Sarah Gurnsey for technical assistance.

\section{REFERENCES}

Gaskin, R.E.; Elliott, G.S.; Munro, J.P. 2000a: Adjuvant technology to reduce spray application volumes on potatoes. Proc. Brighton Crop Protection Conference-Pests \& Diseases. Pp. 687-692.

Gaskin, R.E.; Elliott, G.; Steele, K.D. 2000b: Novel organosilicone adjuvants to reduce agrochemical spray volumes on row crops. N.Z. Plant Prot. 53: 350-354.

Gaskin, R.E.; Murray, R.J.; Steele, K.D.; Stevenson, A. 2001a: Organosilicone surfactant reduces pesticide spray in kiwifruit orchards. In: de Ruiter, H. ed. $6^{\text {th }}$ International Symposium on Adjuvants for Agrochemicals. ISAA 2001 Foundation, Renkum, The Netherlands. Pp. 191-196.

Gaskin, R.E.; Elliott, G.S.; Munro, J.P.; Murray, R.J. 2001b: Improving spray performance on onion crops with novel organosilicone adjuvant blends. In: de Ruiter, H. ed. $6^{\text {th }}$ International Symposium on Adjuvants for Agrochemicals. ISAA 2001 Foundation, Renkum, The Netherlands. Pp. 327-332.

Humble, G.D.; Burga, C.A. 2001: New relationships between spray volume and silicone surfactant use rates in herbicide performance. In: de Ruiter, H. $e d .6^{\text {th }}$ International Symposium on Adjuvants for Agrochemicals. ISAA 2001 Foundation, Renkum, The Netherlands. Pp. 218-223.

Murray, R.J.; Gaskin, R.E.; Grassam, M.R. 1998: Evaluation of a novel adjuvant for use with glyphosate on perennial ryegrass. N.Z. Plant Prot. 51: 162-165.

Underwood, A.; Roberts, S.; Yopp, F. 2001: An overview of the commercial agrochemical and adjuvant markets and trends impacting each for the $21^{\text {st }}$ century. In: de Ruiter, H. $e d .6^{\text {th }}$ International Symposium on Adjuvants for Agrochemicals. ISAA 2001 Foundation, Renkum, The Netherlands. Pp. 608-620. 